\title{
Creencias y actitudes de los jóvenes universitarios granadinos hacia las variedades cultas del español
}

\author{
Antonio Manjón-Cabeza Cruz* \\ Universidad de Granada, España
}

\begin{abstract}
Resumen
PRECAVES XXI permite el estudio de las percepciones y actitudes hacia las variedades del español mediante el uso de la técnica de pares falsos (matched guise). En este trabajo analizamos mediante PRECAVES XXI las actitudes y creencias de estudiantes de Filología Hispánica de Granada (España), centrándonos en la valoración de su propia variedad. Es importante señalar que se trata de un colectivo que en el futuro será un grupo portador del prestigio lingüístico, de modo que sus valoraciones subjetivas deben ser estudiadas por su proyección venidera.

En el caso de Granada, el análisis es interesante porque esta ciudad se inserta en una variedad lingüística minusvalorada en el mundo hispánico, al menos en el ámbito europeo. La estigmatización histórica, unida a la cercanía geográfica con la variedad estándar y a los modernos procesos de globalización, está llevando a un proceso de convergencia o asimilación con el estándar.
\end{abstract}

* Para correspondencia, dirigirse a: Antonio Manjón-Cabeza Cruz (amanjoncabeza@ugr. es), Universidad de Granada, España. Departamento de Lengua Española, Facultad de Filosofía y Letras, Universidad de Granada, E - 18071 GRANADA, España. Campus de Cartuja s.n. 
Esto hace que los hablantes muestren unas tendencias contradictorias que revelan la pugna entre la lealtad a la variedad vernácula y la asunción de modelos de prestigio estatales. Esa pugna siempre aparece mediatizada por tópicos recurrentes: preeminencia de la escritura, carácter rural y tradicional de la sociedad andaluza, etc.

Palabras clave: creencias lingüísticas, actitudes lingüísticas, variedades del español, PRECAVES XXI, Granada, España.

\title{
Beliefs AND ATTITUdes of YOUNG GRANADA UNIVERSITY STUDENTS TOWARDS THE EDUCATED VARIETIES OF SPANISH
}

\begin{abstract}
PRECAVES XXI allows you the study of the perceptions and attitudes towards Spanish varieties using the matched guise technique. In this paperwork we analyse the attitudes and beliefs from Spanish philology students in Granada (Spain), focusing on the assessment of their own variety. It is important to point out that it is a collective who, in the future, will be a group wielding the linguistic prestige, so their subjective assessments shall be studied for their future projection. In the case of Granada, the analysis is interesting because this city is placed in an underestimated linguistic variety in the Hispanic world, at least in the European sphere. The historical stigmatization along with the geographic proximity with the standard variety and the modern globalization processes are leading to a process of convergence or assimilation to the standard.

This drives the speakers to show contradictory tendencies that reveals the struggle between loyalty to the vernacular variety and the assumption of the state prestige models. This fight always appears mediatised by the recurrent topics: the writing pre-eminence, the rural and traditional character of the Andalusian society, etc.
\end{abstract}

Keywords: Linguistics beliefs, linguistics attitudes, varieties of Spanish, PRECAVES XXI, Granada, Spain.

Recibido: $29 / 01 / 18$

Aceptado: 16/04/18 


\section{INTRODUCCIÓN}

En el marco de los estudios sobre valoraciones subjetivas cobran especial importancia los dedicados a los llamados transmisores del prestigio lingüístico (García y Fuentes 1996). Los grupos que podemos considerar portadores y transmisores del prestigio son variados, pero no podemos dejar de señalar (Manjón-Cabeza 2000) tanto por su consideración social prestigiosa como por su quehacer en el mercado lingüístico a periodistas, políticos, religiosos y docentes.

Este trabajo ${ }^{1}$ se dedica al estudio de uno de estos colectivos: los futuros profesores de español, tanto en su consideración como lengua propia, como en su vertiente como lengua extranjera. Esto es así ya que la muestra ha estado constituida en su totalidad por jóvenes universitarios granadinos que cursan estudios de Filología Hispánica, que son los que en España cubren con preferencia la docencia de las distintas materias de lengua y literaturas españolas en educación secundaria y en la enseñanza del español como lengua extranjera. El horizonte profesional de la mayoría de estos jóvenes está, pues, relativamente delimitado.

Dadas las características básicas tanto de la metodología seguida, que se puede consultar en el artículo primero de este monográfico (Cestero y Paredes 2018) donde se explica el marco teórico y la metodología de PRECAVES XXI, como de la muestra, creemos que debemos abordar en este acercamiento tres asuntos principales:

a) El prestigio de las variedades, de modo que debemos responder a la pregunta siguiente: ¿Para los sujetos estudiados existe alguna variedad de español que pueda considerarse mejor o más prestigiosa?

b) Identificación y valoración del resto de variedades, ya que parece obligatorio tener que responder a la pregunta: ¿En qué medida los estudiantes granadinos identifican y valoran el resto de variedades cultas del español?

c) Percepción de la variedad propia; es decir, debemos intentar responder a la siguiente cuestión: ¿Qué percepción tienen los futuros docentes granadinos de su propia variedad?

\footnotetext{
Este estudio se ha realizado en el marco del Proyecto ECOPASOS-Granada financiado por MINECO/FEDER (Ref. FFI2015-68171-C5-2-P), integrado en el proyecto PRESEEA (Proyecto para el estudio sociolingüístico del español de España y América).
} 
El análisis de este último apartado constituirá el grueso del trabajo, ya que la zona estudiada muestra unas peculiaridades con respecto a otras zonas de habla española que la hacen especialmente interesante. Estas peculiaridades debemos abordarlas de mayor a menor. En primer lugar, citaremos algunas singularidades andaluzas y, en segundo lugar, las características granadinas. Para ello deberemos ceñirnos a las distintas variedades del español de Europa.

Aunque el origen cronológico de algunos rasgos fonéticos andaluces es discutido, como se puede comprobar en Frago (1993: 55 y ss), Lapesa (2008 246) o en Cano Aguilar (2013), donde se hace una revisión crítica de las diferentes propuestas, parece indudable que, al menos desde el siglo XVI, como demostró De Bustos (1981: 223), hay conciencia de que el español de Andalucía tiene unas características peculiares si se compara con el español de Castilla. A pesar de que algunos testimonios tempranos aluden, como, por otra parte, parece esperable, a características léxicas (Narbona, Morillo y Velarde 1987: 47), sin duda es el componente fónico el que acumula las diferencias con otras variedades del español.

Tras la fijación de la capitalidad en Madrid, y por avatares sociohistóricos diversos, el proceso de normalización lingüística llevó a que en el español de Europa el estándar fuese el de Castilla. Se inicia así un proceso de estigmatización de las otras variedades europeas que llega a nuestros días.

La estigmatización de los rasgos andaluces tiene dos vertientes:

a) Hay procesos de estigmatización interna, puesto que los andaluces estigmatizan ciertas variantes por la actuación de diversas valoraciones subjetivas (actitudes y creencias). De los muchos rasgos que ha sufrido este tipo de proceso recordemos ahora la estigmatización del llamado ceceo, del heheo o de la variante palatal fricativa $/ \mathrm{J} /$. Ni qué decir tiene que todos los rasgos con estigmatización interna cuentan además con estigmatización externa.

b) Existen también procesos de estigmatización externa, es decir, hay fenómenos que en andaluz no son valorados negativamente, pero sobre los que pesan valoraciones negativas por parte de muchos usuarios de la variedad estándar. Es el caso de la pérdida de la /-s/ o de la concordancia ustedes +2 . ${ }^{\text {a }}$ persona del plural, propia del oeste andaluz.

Prueba de estas consideraciones negativas son las calificaciones dadas al andaluz por los madrileños, como reflejan los datos de Yraola (2014) o los toledanos, como se puede consultar en Manjón-Cabeza (2000) o Crespo y Manjón-Cabeza (1996). 
La creciente estigmatización, unida a la cercanía geográfica con la variedad estándar y a los modernos procesos de globalización o influencia de los medios de comunicación masivos, ha llevado a un proceso de convergencia (Villena Ponsoda 2006) con el estándar, o proceso de asimilación como quieren otros (Moreno Cabrera 2000).

Si nos centramos en la variedad granadina hay que resaltar dos peculiaridades:

a) Los procesos de convergencia están más avanzados en la parte oriental de Andalucía (Granada) que en la occidental (Sevilla), lo que está llevando o ha llevado a la existencia de una estratificación sociolingüística de la sociedad que podemos calificar de abrupta.

b) Por motivos políticos, ciertos grupos han fomentado una rivalidad social y cultural entre la capital andaluza, Sevilla, y otras ciudades, entre las que se encuentra Granada. Lo que puede hacernos sospechar que pudiera existir rechazo por fenómenos lingüísticos que los hablantes achacan a la zona de influencia sevillana.

Estos hechos sociolingüísticos han llevado al andaluz a ser objeto de numerosísimos estudios, incluyendo recopilaciones bibliográficas como las de Mondéjar (2006), quien anotó 1428 publicaciones solo hasta el año de la segunda edición. Claro está que en esos estudios no faltan los que tratan las actitudes y creencias, casi siempre con pretensiones de repercusión posterior en estudios de política y planificación lingüística (De Molina Redondo, 1985). Quizá el primer estudio importante es el de Alcaraz et al. (1979) y en la larga nómina posterior podemos citar a Vaz de Soto (1981), García y Manjón-Cabeza (1989), Bustos Tovar (1996), Fuentes González (1996), Martínez y Moya (2000), García Marcos (2008), y un largo etcétera.

No está de más recordar que algunos de estos estudios han sido objeto de agrias diatribas por parte de algunos estudiosos que intentaban defender la idea del monolitismo del español, relegando la realidad sociolingüística andaluza al ámbito de lo pintoresco, dialectal y anecdótico. Las terribles palabras de Mondéjar (1985: 65) no dejan lugar a dudas sobre esa postura: "resulta que el andaluz que contribuiría a afianzar nuestras señas de identidad sería el más pobre y el menos apto para expresar el más mínimo concepto cultural o científico". No debe olvidarse para la justa interpretación de estas palabras que las características diferenciadoras del andaluz son esencialmente fónicas ${ }^{2}$.

2 Seguramente por esa posición de detentadores científicos de lo andaluz se explica el tono despectivo y muchas veces insultante que han recibido algunos estudios sobre actitudes, 
Ahora, con el proyecto PRECAVES XXI tenemos una gran oportunidad de actualizar y profundizar en las valoraciones subjetivas, máxime cuando hay equipos en dos de los polos del andaluz: Granada y Sevilla. Además, el proyecto permitirá la comparación con otras modalidades del español tanto de Europa como de América.

\section{METODOLOGÍA}

Hemos señalado que la muestra está muy circunscrita: son estudiantes de Filología Hispánica de la Universidad de Granada, todos nacidos en la provincia de Granada. Esta limitación geográfica implica limitaciones demográficas $^{3}$ importantes, por lo que se acerca mucho al ideal de la propuesta del proyecto PRECAVES XXI pero no la alcanza, como podemos observar en la tabla 1:

\begin{tabular}{|l|l|c|}
\hline \multicolumn{2}{|c|}{ GRANADA } & N \\
\hline \multirow{2}{*}{ SEXO } & Mujeres & 66 \\
\cline { 2 - 3 } & Hombres & 23 \\
\hline \multirow{2}{*}{ COLECTIVO } & Sin formación en variedades & 49 \\
\cline { 2 - 3 } & Con formación en variedades & 40 \\
\hline \multirow{2}{*}{ TOTAL } & 89 \\
\hline
\end{tabular}

Tabla 1. Características de la muestra

Observamos que tenemos dos grandes grupos: 49 estudiantes iniciales del grado, que no han tenido formación específica en variedades del español, y 40 estudiantes de los cursos finales del grado, que ya han cursado distintas materias directamente relacionadas con las variedades del español, lo que nos da un total de 89 estudiantes. Hemos distinguido para este estudio el

creencias y política lingüística subsiguiente. No podemos olvidar los adjetivos sandez (Alvar 1999) y estupidez (Salvador 1997 apud Narbona 2009) propinados por dos estudiosos clásicos del andaluz, olvidando el decoro científico.

3 En un principio contábamos con 108 encuestados, pero al eliminar las encuestas abandonadas al principio por parte del informante y a aquellas personas que rebasaban los límites de edad y de procedencia geográfica, se nos redujo a los 89 con los que razonaremos. 
sexo de los encuestados. Como era de esperar, dada la adscripción social de la enseñanza en España, la mayoría de la muestra está constituida por mujeres, quienes casi triplican la tasa masculina.

Todas las encuestas se realizaron en el año 2017, la mayoría (79) en el año 2017 y solo diez a fines del año anterior. De los encuestados, 50 eran nacidos en la capital y el resto, 39, en distintas localidades de la provincia.

Para el análisis de los resultados se han utilizado análisis básicos de datos absolutos y porcentajes obtenidos directamente de las hojas de cálculo generadas por el proyecto. Asimismo, en muchas ocasiones, como se verá en el siguiente apartado, se han realizado pruebas de significación. Esto se ha hecho para intentar comprobar si alguna de las variables estudiadas influye significativamente en las valoraciones subjetivas. Estas variables han sido:

a) Sexo de los encuestados (mujer u hombre)

b) Colectivo al que pertenece (sin o con formación en variedades del español)

c) Discurso evaluado (oral o leído)

d) Voz evaluada (voz de mujer o voz de hombre)

Para las pruebas de significación hemos utilizado el programa de análisis estadístico IBM SPSS 20. Dentro de las posibilidades de análisis que podíamos hacer, hemos escogido dos:

a) Determinación del $\chi 2$ de Pearson mediante tablas de contingencia.

b) Determinación de p-valor mediante la prueba de comparación de medias (ANOVA de un factor). Esto se ha llevado a cabo en los casos en los que no era posible la aplicación de la prueba anterior al haber casillas vacías que conllevaban una frecuencia inferior a la mínima esperada ${ }^{4}$.

$4 \quad$ Ante la imposibilidad de mostrar todos los cálculos, los resultados completos de las pruebas estadísticas están disponibles bajo demanda al autor. 


\section{RESULTADOS}

\subsection{Prestigio de Las Variedades}

Los encuestados se dividen entre aquellos que consideran que hay variedades mejores que otras y aquellos que consideran que no se puede señalar alguna donde se hable mejor español. Los datos aparecen en la tabla 2.

\begin{tabular}{|l|l|l|}
\hline & $\mathrm{n}$ & $\%$ \\
\hline Castilla y norte de España & 35 & 39,33 \\
\hline Andalucía & 7 & 7,87 \\
\hline América & 4 & 4,49 \\
\hline España & 3 & 3,37 \\
\hline En todas por igual & 37 & 41,57 \\
\hline No contesta & 3 & 3,37 \\
\hline Total & 89 & 100,00 \\
\hline
\end{tabular}

Tabla 2. Región o zona donde se habla mejor español

Podemos observar que hay más encuestados que expresan que hay jerarquía en las variedades $(55,06 \%$ del total). Es evidente que la variedad que los granadinos encuestados anotan como mejor es la castellana $(39,33 \%$ del total). Llama la atención la actuación de un tópico arraigado puesto que de los 9 encuestados que optan por anotar una ciudad concreta como modelo del buen español, 6 eligen Valladolid y solo dos, Madrid. De todas formas, la preferencia de estos encuestados (13 casos) es anotar un genérico Castilla, generalmente en su versión oficial: Castilla y León, aunque no faltan las referencias al centro de España, norte de España y similares.

Las otras opciones, dentro de los que establecen jerarquías de modalidades son claramente minoritarias y solo el 7,87\% muestra el prurito localista de señalar su propia modalidad.

No llega a la mitad $(41,57 \%)$, pero no es un dato desdeñable, el porcentaje que opina que no se puede señalar una variedad mejor que otra. Es, además, importante, como se observa en la tabla 3, que el factor que condiciona claramente esa elección es el colectivo, como se puede observar por el valor de $\chi^{2}<0,05$. 


\begin{tabular}{|l|l|c|c|c|}
\hline \multirow{2}{*}{ Colectivo } & $\begin{array}{l}\text { Sin formación } \\
\text { en variedades }\end{array}$ & $35 / 71,4 \%$ & $12 / 32,4 \%$ & \multirow{2}{*}{$\chi^{2}=0,000$} \\
\cline { 2 - 4 } & $\begin{array}{l}\text { Con formación } \\
\text { en variedades }\end{array}$ & $14 / 28,6 \%$ & $25 / 67,6 \%$ & \\
\hline \multirow{2}{*}{ Sexo } & Mujeres & $36 / 73,5 \%$ & $27 / 73,0 \%$ & \multirow{2}{*}{$\chi^{2}=0,575$} \\
\cline { 2 - 4 } & Hombres & $13 / 26,5 \%$ & $10 / 27,0 \%$ & \\
\hline \multirow{2}{*}{ Voz evaluada } & Voz de mujer & $27 / 55,1 \%$ & $14 / 37,8 \%$ & \multirow{2}{*}{$\chi^{2}=0,085$} \\
\cline { 2 - 4 } & Voz de hombre & $22 / 44,9 \%$ & $23 / 62,2 \%$ & \\
\hline
\end{tabular}

Tabla 3. Factores que influyen en el establecimiento de jerarquías o no en la valoración general de variedades (datos y porcentajes)

Se puede observar en la tabla 3 que el colectivo sin formación en materias o asignaturas de variedades del español, en su mayoría, opta por el establecimiento de jerarquías $(71,4 \%)$, mientras que en el colectivo con formación en variedades la proporción casi se invierte y elige la opción de igualdad de variedades en un $67,7 \%$.

\subsection{IDENTIFICACIÓN Y VALORACIÓN DE VARIEDADES}

En lo tocante a la identificación de las variedades, hay que hacer notar que, aunque se permite la adscripción libre y, por tanto, la casuística es complicada, hemos establecido cuatro grupos o grados en la identificación. Así, como se puede observar en la tabla 4, distinguimos los casos claros de acierto, como cuando, por ejemplo, se anota Argentina o Uruguay para una grabación de la variedad rioplatense; las contestaciones erróneas, como cuando se anota México para la variedad andaluza; las genéricas, sobre todo cuando se anota Latinoamérica, Hispanoamérica y similares para cualquier variedad americana, pero también cuando se optó por España para una variedad española. Por supuesto, también se anota la opción de no contestar. 


\begin{tabular}{|c|c|c|c|c|c|}
\hline VARIEDAD & & $\mathrm{n} / \%$ & VARIEDAD & & $\mathrm{n} / \%$ \\
\hline \multirow[t]{5}{*}{ Castellana } & Grabaciones & 177 & \multirow[t]{5}{*}{ ANDINA } & Grabaciones & 175 \\
\hline & Acertadas & $129 / 72,88 \%$ & & Acertadas & $\begin{array}{c}43 / \\
24,57 \%\end{array}$ \\
\hline & Erróneas & $9 / 5,08 \%$ & & Erróneas & $\begin{array}{c}63 / \\
36,00 \%\end{array}$ \\
\hline & Genéricas & $38 / 21,47 \%$ & & Genéricas & $\begin{array}{c}63 / \\
36,00 \%\end{array}$ \\
\hline & no contesta & $1 / 0,56 \%$ & & no contesta & $6 / 3,43 \%$ \\
\hline \multirow[t]{5}{*}{ CANARIA } & Grabaciones & 173 & \multirow[t]{5}{*}{ Chilena } & Grabaciones & 172 \\
\hline & Acertadas & $77 / 44,51 \%$ & & Acertadas & $9 / 5,23 \%$ \\
\hline & Erróneas & $72 / 41,62 \%$ & & Erróneas & $\begin{array}{c}97 / \\
56,40 \% \\
\end{array}$ \\
\hline & Genéricas & $14 / 8,09 \%$ & & Genéricas & $\begin{array}{c}58 / 33 \\
72 \%\end{array}$ \\
\hline & no contesta & $10 / 5,78 \%$ & & no contesta & $8 / 4,65 \%$ \\
\hline \multirow[t]{5}{*}{ Mexicana } & Grabaciones & 175 & \multirow[t]{5}{*}{ RioplatensE } & Grabaciones & 176 \\
\hline & Acertadas & $55 / 31,43 \%$ & & Acertadas & $\begin{array}{c}142 / \\
80,68 \% \\
\end{array}$ \\
\hline & Erróneas & $58 / 33,14 \%$ & & Erróneas & $13 / 7,39 \%$ \\
\hline & Genéricas & $53 / 30,29 \%$ & & Genéricas & $\begin{array}{c}18 / \\
10,23 \% \\
\end{array}$ \\
\hline & no contesta & $9 / 5,14 \%$ & & no contesta & $3 / 1,70 \%$ \\
\hline \multirow[t]{5}{*}{ CARIBEÑA } & Grabaciones & 178 & \multirow[t]{5}{*}{ ANDALUZA } & Grabaciones & 177 \\
\hline & Acertadas & $42 / 23,60 \%$ & & Acertadas & $\begin{array}{c}135 / \\
76,27 \% \\
\end{array}$ \\
\hline & Erróneas & $70 / 39,33 \%$ & & Erróneas & $11 / 6,21 \%$ \\
\hline & Genéricas & $60 / 33,71 \%$ & & Genéricas & $\begin{array}{c}25 / \\
14,12 \% \\
\end{array}$ \\
\hline & no contesta & $6 / 3,37 \%$ & & no contesta & $6 / 3,39 \%$ \\
\hline
\end{tabular}

Tabla 4. Identificación de las grabaciones del conjunto de variedades. Datos absolutos y porcentajes

Se observan en la tabla 4 grandes disparidades en la identificación de variedades. Si ordenamos de mayor a menor el grado de acierto, obtenemos el gráfico 1. 


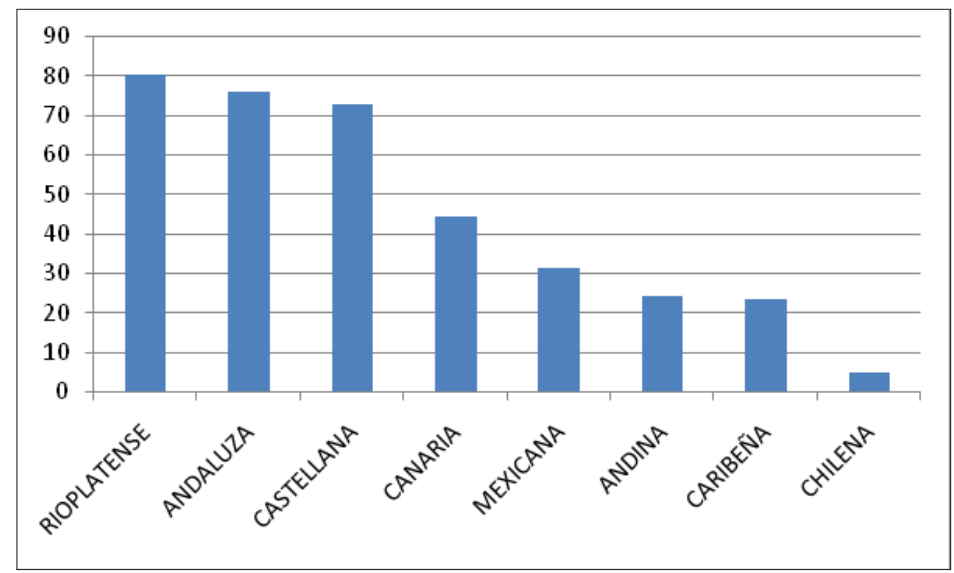

Gráfico 1. Porcentajes de identificación correcta de las variedades estudiadas

Aunque con matices, podemos afirmar que las variedades más cercanas a los encuestados, es decir, las europeas, son mejor identificadas que las americanas. Hay que resaltar que la variedad rioplatense es una excepción a esa tendencia ya que obtiene el mayor grado de identificación $(80,68 \%)$, seguramente por la identificación de la pronunciación rehilada del fonema palatal, como veremos más adelante. En el extremo opuesto se sitúa el grado de identificación de la variedad chilena, que solo muestra un grado de identificación del 5,23\%.

El relativo bajo grado de identificación $(44,51 \%)$ de la variedad canaria respecto a las otras dos variedades de España se explica por el elevado porcentaje de calificaciones erróneas $(41,62 \%)$, atribuible casi por igual tanto a errónea identificación con variedades americanas como a identificación con la variedad andaluza.

Las preguntas 2 y 3 de la encuesta son de respuesta abierta y permiten al encuestado señalar los aspectos que más le gustan o disgustan del texto valorado. No todos los encuestados rellenan estos apartados y hay una gran diversidad de opiniones, pero se pueden apuntar algunas respuestas que se repiten. Muchas veces, algún aspecto lingüístico es valorado positivamente por ciertos encuestados, mientras que el mismo aspecto es valorado negativamente por otros encuestados. Si hacemos un resumen observamos lo siguiente:

a) De la variedad castellana se tiende a valorar negativamente la monotonía o lentitud al hablar, mientras que las valoraciones positivas mencionan la pronunciación clara y pausada. A esto se suma la 
pronunciación de todos los fonemas o pronunciación exacta. Parece claro, ante estas respuestas, que en los encuestados la buena o mala pronunciación está relacionada con la escritura ${ }^{5}$. Hay algunos casos en que esto se explicita: es positiva la pronunciación de todas las letras.

b) Lo más negativo de la variedad andaluza es, otra vez, la supuesta no pronunciación de todas las vocales o consonantes ${ }^{6}$. Los aspectos positivos se centran, como es esperable, en la cercanía, aunque también se anotan tópicos que tienen que ver con la alegría y con que es una variedad divertida.

c) La variedad canaria tiene pocos comentarios negativos. Los comentarios positivos se inclinan por la dulzura de sus hablantes, aunque también se valora positivamente su seseo.

d) La valoración de la modalidad mexicana coincide en parte con la de la castellana puesto que los encuestados andaluces creen negativa la lentitud al hablar y el uso excesivo de este. Los aportes positivos tienen que ver con la claridad, aunque también se menciona que es una variedad que les parece alegre.

e) Para la variedad del Caribe el seseo es valorado tanto positivamente como negativamente. Los encuestados le achacan excesiva lentitud, mientras que consideran muy agradables la aspiración de la /x/ y la musicalidad.

f) Al igual que en el caso anterior, el seseo andino es valorado como característica positiva y negativa. Muchos encuestados valoran positivamente la claridad en los textos de la variedad andina.

g) De la variedad chilena no podemos anotar nada significativo por el poco acierto de los encuestados, mientras que sí podemos hacerlo de la modalidad rioplatense. Como en algún otro caso, hay un aspecto fónico que unos estudiantes granadinos consideran negativo y otros, positivo: el rehilamiento. Es negativa la caracterización de lentitud y monotonía de la variedad, así como el uso excesivo de este; mientras que se valora bien la melodía.

\footnotetext{
5 Parece tarea imposible convencer a estos alumnos de que las letras no se pronuncian: las letras se leen o se escriben. Es esta una queja de muchos profesores universitarios, como se puede comprobar en Romera Barrios (1999).

6 Llama la atención el tópico de que los andaluces eliminan vocales en su discurso. Eso no ocurre ni siquiera tomando la referencia de la escritura.
} 
La encuesta del proyecto PRECAVES XXI dedica parte de su espacio a la valoración directa e indirecta de las variedades. Desborda el propósito de este trabajo el comentario pormenorizado de estas valoraciones para todas las variedades, pero, como orientación, se pueden consultar las tablas 5 y 6. Debe observarse que estos datos se han obtenido únicamente con las respuestas acertadas de cada variedad, que se pueden consultar en la tabla 4. Quiere esto decir que hay que ser muy cauto con aquellas variedades con pocos aciertos, en especial con la chilena, ya que solo se han considerado nueve respuestas en ese caso.

En la Tabla 5 se muestran las medias de las valoraciones directas cognitivas, afectivas y general. En la Tabla 6 se recogen las medias generales de las valoraciones indirectas de las variedades estudiadas.

\begin{tabular}{|l|c|c|c|}
\hline VARIEDAD & $\begin{array}{c}\text { Media } \\
\text { cognitiva }\end{array}$ & $\begin{array}{c}\text { Media } \\
\text { afectiva }\end{array}$ & Media general \\
\hline CASTELLANA & 4 & 3,6 & 3,8 \\
\hline ANDALUZA & 3,6 & 4,0 & 3,8 \\
\hline CANARIA & 3,9 & 4,1 & 4,0 \\
\hline MEXICANA & 3,8 & 4,4 & 4,1 \\
\hline CARIBENA & 3,9 & 4,4 & 4,2 \\
\hline ANDINA & 3,7 & 3,8 & 3,7 \\
\hline CHILENA & 3,5 & 4,5 & 4,0 \\
\hline RIOPLATENSE & 3,8 & 4,0 & 3,9 \\
\hline
\end{tabular}

Tabla 5. Medias de las valoraciones directas de las variedades

Se puede observar en la tabla 5 que las medias generales de las valoraciones son, en general, altas. También se puede comprobar que hay diferencias entre las valoraciones afectivas y cognitivas. Las variedades con medias más altas desde el punto de vista cognitivo son la castellana, la canaria y la caribeña. Resulta llamativo que una de las variedades que alcanza menos valoración cognitiva sea la propia de los encuestados. Datos relativamente opuestos son los que aparecen en las medias de valoración afectiva. Ahora es la variedad castellana la peor valorada. Son reseñables también las altas valoraciones afectivas de variedades americanas como la caribeña y la mexicana.

\begin{tabular}{|l|c|c|}
\hline VARIEDAD & $\begin{array}{c}\text { Nivel } \\
\text { Socioeconómico }\end{array}$ & $\begin{array}{c}\text { Características } \\
\text { Personales }\end{array}$ \\
\hline CASTELLANA & 2,8 & 4,3 \\
\hline
\end{tabular}




\begin{tabular}{|l|l|l|}
\hline CANARIA & 2,5 & 4,8 \\
\hline MEXICANA & 2,1 & 4,6 \\
\hline CARIBENA & 2,5 & 4,7 \\
\hline ANDINA & 2,3 & 4,1 \\
\hline CHILENA & 2,4 & 4,7 \\
\hline RIOPLATENSE & 2,5 & 4,4 \\
\hline ANDALUZA & 2,3 & 4,5 \\
\hline
\end{tabular}

Tabla 6. Valoraciones indirectas de las variedades estudiadas (medias generales)

En la tabla 6 se muestra el resultado de las preguntas 5,6 y 7 de la encuesta, donde se valora socioeconómicamente a la persona que habla (nivel socioeconómico según renta, trabajo y estudios) y el resultado de la pregunta 11, donde se valora las características personales de la persona que habla (inteligente, simpática, educada, cercana, culta). Para la valoración económica la escala va de 1 a 3 , mientras que la valoración de las características personales tiene el rango de 1 a 6 .

Si analizamos someramente la tabla 6 , observamos que las valoraciones son todas altas, es decir, los encuestados tienen tendencia a no discriminar a las personas, pero hay algunas diferencias, que pasamos a comentar con brevedad.

En la valoración socioeconómica hay una variedad considerada como de nivel alto: la castellana; cuatro podemos adscribirlas al nivel medio: canaria, caribeña, chilena y rioplatense; y tres se pueden catalogar como de nivel bajo: andina, andaluza y, especialmente, la mexicana. Alguna de estas medias deberá ser comentada en el apartado siguiente, que trata la consideración de la propia variedad.

En cuanto a la valoración de las características personales, encontramos algunos cambios con respecto a la valoración socioeconómica. De este modo, podemos hablar de cuatro variedades cuyos hablantes son altamente valorados: canaria, caribeña, mexicana y chilena (en este último caso, con la salvedad de su poca representatividad), tres de las variedades tienen una valoración intermedia: andaluza, rioplatense y castellana, mientras que la variedad andina queda algo peor valorada con una media de 4,1.

Sin duda, estos datos requieren un tratamiento más minucioso que debemos postergar para trabajos futuros. 


\subsection{PERCEPCIÓN DE LA VARIEDAD PROPIA}

\subsubsection{Grado de acierto}

Si nos centramos en la valoración que los estudiantes granadinos hacen del andaluz, debemos hacer notar, en primer lugar, que el acierto en la identificación es bastante alto, como se desglosa en la tabla 7.

\begin{tabular}{|l|c|}
\hline GRABACIONES VALORADAS & 1406 \\
\hline GRABACIONES ANDALUZAS & 177 \\
\hline ACERTADAS & 135 \\
\hline $\begin{array}{c}\text { ERRÓNEAS } \\
\text { España (7) } \\
\text { América (4) }\end{array}$ & 11 \\
\hline GENÉRICAS & 25 \\
\hline NO CONTESTA & 6 \\
\hline $\begin{array}{c}\text { FALSOS ANDALUCES } \\
\text { Castilla (9) } \\
\text { Canarias (28) } \\
\text { México (1) } \\
\text { Caribe (1) } \\
\text { Chile (9) }\end{array}$ \\
\hline
\end{tabular}

Tabla 7. Identificación de las grabaciones andaluzas

Para la correcta interpretación de la tabla 7 hay que tener en cuenta que 135 grabaciones andaluzas fueron identificadas como tal por los encuestados. Encontramos muy pocos errores directos (11 casos), es decir, asignaciones de grabaciones andaluzas a otras variedades de España o de América. Mayores son los casos de asignación genérica (25 encuestas), casi siempre adscritas a "España". Los errores indirectos o falsos andaluces son 48 casos de grabaciones de otras variedades que son adscritas erróneamente al andaluz. Se puede deducir con facilidad que la confusión más relevante se da con la variedad canaria. Asimismo, junto con las anecdóticas atribuciones erróneas a las modalidades mexicanas y caribeñas, las atribuciones a Castilla parecen comentables, porque parecen indicar que los errores se dan, sobre todo, con variedades de Europa. Caso aparte son las nueve confusiones con la modalidad chilena. Seguramente la falta de identificación de la variedad (como se muestra en la tabla 4) hace que aparezcan esos casos. 
Los factores que parecen influir en estas equivocaciones indirectas son, en parte, esperables. De este modo, se equivocan más los estudiantes del colectivo que aún no ha tenido asignaturas de variedades del español (33 frente a 15 del otro colectivo) y también es mayor el número de yerros en los textos orales leídos que en los más espontáneos (también 33 frente a 15). Parece evidente que la lectura de textos conlleva la utilización de formas más prestigiosas que pueden diluir algunas características diferenciadoras de las modalidades.

Más difícil de explicar es la evidente diferencia entre las voces masculinas y femeninas evaluadas. Resulta que hay 38 voces femeninas erróneamente evaluadas frente a solo 10 voces masculinas con atribución errónea. Si tenemos en cuenta que 45 alumnos evaluaron voces de hombre y 44 alumnos evaluaron voces de mujer, es decir, un número casi igual, sospechamos que se trata de un factor que hay que tener en cuenta. Quizá podamos aventurar la hipótesis, siguiendo a Trudgill (1983), de que, al ser las mujeres las portadoras del prestigio lingüístico en las sociedades modernas, sus grabaciones también tiendan a minimizar alguna característica de su variedad, con lo que hay mayor grado de confusión al evaluar voces de mujeres que de hombre, que mantendrían más lealtad al vernáculo.

Ha de tenerse en cuenta, para los datos y comentarios que siguen, que solo se han tenido en cuenta las grabaciones acertadas. Los resultados de la evaluación de los falsos andaluces son casi siempre coincidentes con los de las grabaciones acertadas. En adelante, solo nos referiremos a las valoraciones erróneas cuando supongan alguna desviación con respecto a las acertadas.

\subsubsection{Identificación con las grabaciones}

Un punto importante de la encuesta es la expresión del grado de identificación de los encuestados con la persona que habla, con seis posibilidades de identificación. Los resultados para los estudiantes granadinos se muestran en la tabla 8 .

\begin{tabular}{|l|c|l|c|}
\hline \multicolumn{2}{|l|}{$\begin{array}{l}\text { Voces andaluzas identificadas } \\
\text { correctamente }(\mathrm{n}=135)\end{array}$} & $\begin{array}{l}\text { Voces incorrectamente identificadas } \\
\text { como andaluzas }(\mathrm{n}=47)\end{array}$ \\
\hline NO IDÉNTICA & $14,81 \%$ & NO IDÉNTICA & $36,17 \%$ \\
\hline Totalmente diferente & $1,48 \%$ & Totalmente diferente & $6,38 \%$ \\
\hline Bastante diferente & $5,93 \%$ & Bastante diferente & $17,02 \%$ \\
\hline Ligeramente igual & $7,41 \%$ & Ligeramente igual & $12,77 \%$ \\
\hline IDÉNTICA & $85,19 \%$ & IDÉNTICA & $63,83 \%$ \\
\hline
\end{tabular}




\begin{tabular}{|l|c|l|c|}
\hline Ligeramente diferente & $30,37 \%$ & Ligeramente diferente & $27,76 \%$ \\
\hline Bastante igual & $46,67 \%$ & Bastante igual & $31,91 \%$ \\
\hline Totalmente idéntica & $8,15 \%$ & Totalmente idéntica & $4,26 \%$ \\
\hline
\end{tabular}

Tabla 8. Identidad de los encuestados con las voces andaluzas evaluadas

Debe observarse que en la tabla 8 hemos anotado también los resultados de las voces identificadas incorrectamente porque hay algunas diferencias.

En las columnas de la izquierda están los datos más importantes, que nos muestran que los granadinos tienden a identificarse con las personas que hablan, puesto que si se suman las tres que podemos calificar como de identificación idéntica obtenemos un mayoritario $85,19 \%$; pero tenemos que llamar la atención que la identificación total -con $8,15 \%$ - no es la que obtiene un porcentaje más elevado. Creemos que ese dato da cuenta de que hay una identificación con la voz andaluza, pero que también puede haber conciencia de la variación lingüística entre el oriente (Granada) y el occidente (Sevilla) andaluz.

Si hemos incluido las columnas de la derecha de la tabla 8 es porque la identificación de los encuestados con las voces incorrectamente identificadas como andaluzas muestra diferencias con las correctas. Se puede observar que la identificación es menor en el caso de las incorrectas. De este modo, se observa que, aunque predomina la identificación, se pasa de un $85,19 \%$ a un $63,83 \%$, de manera que aumenta la no identificación de manera paralela. Este dato puede parecer baladí, pero creemos que no es así porque demuestra la bondad de la encuesta. Si los datos fuesen similares podríamos sospechar que la identificación se hace de manera localista (es una voz andaluza, y, por tanto, me identifico con ella), pero no es así puesto que, al no ser voces andaluzas, aunque los encuestados así lo crean, el grado de identificación es menor.

\subsubsection{Valoraciones directas del andaluz}

Las valoraciones directas de la propia variedad nos arrojan los datos generales que aparecen en el gráfico 2. 


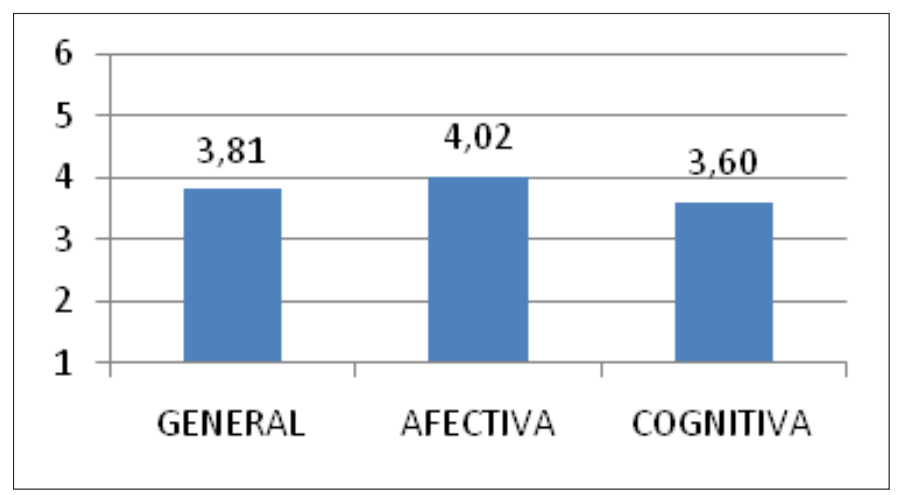

Gráfico 2. Valoraciones directas del andaluz. Datos generales

Ha de tenerse en cuenta que la escala va de 1 a 6 , luego el valor intermedio de la escala está en 3,5, de modo que la valoración general es ligeramente positiva. También es evidente, a la vista del gráfico 2, que hay disparidad entre las valoraciones afectivas y las cognitivas, puesto que las primeras son más claramente positivas.

En los gráficos 3 y 4 se muestran los valores de las distintas propiedades afectivas y cognitivas que conforman la valoración directa de las grabaciones andaluzas correctamente identificadas.

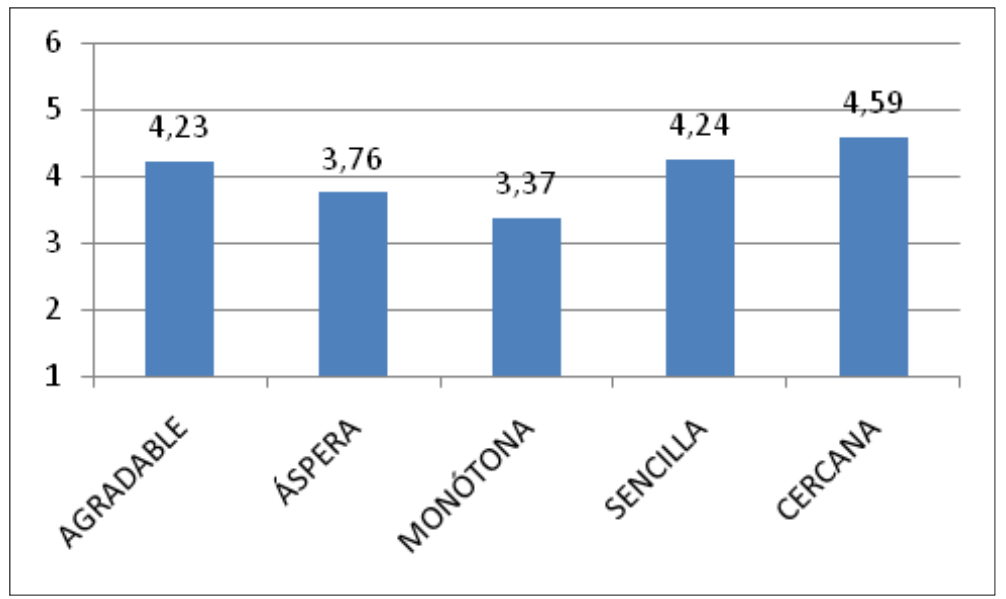

Gráfico 3. Valoraciones directas del andaluz. Datos particulares (1) 


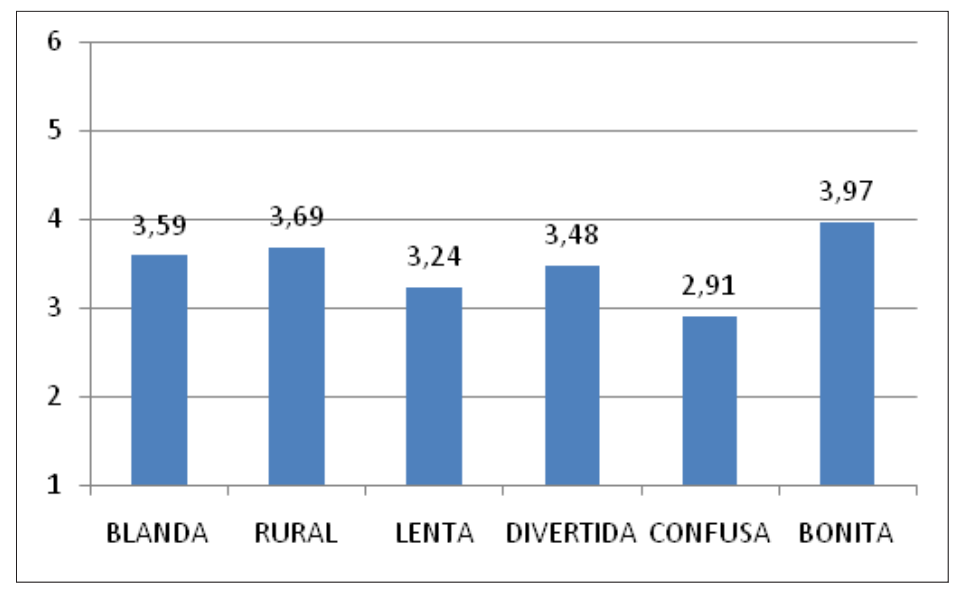

Gráfico 4. Valoraciones directas del andaluz. Datos particulares (2)

Como el valor intermedio de la escala se sitúa en 3,5, comprobamos que hay valoraciones altas, sobre todo en lo que toca a la cercanía, sencillez y carácter agradable. Como aspectos negativos debemos resaltar la aspereza y el carácter rural que los encuestados tienden a atribuir a las voces evaluadas.

Para cada factor de los que aparecen en los gráficos 3 y 4 hemos aplicado la prueba de comparación de medias (ANOVA de un factor), para comprobar si alguna variable de las estudiadas (sexo, colectivo, tipo de discurso, voz evaluada $^{7}$ ) influyen significativamente en la variación de las valoraciones directas.

Los p-valor significativos no se dan para todas las variables. Pasamos a enumerar los hallados y comentaremos alguno de ellos:

1) Agradable/desagradable. Es significativa la relación con el colectivo ( $p$-valor $=0,039$ ), puesto que el colectivo con estudios de variedades de español tiene tendencia a dar una nota más alta en este apartado. Asimismo, es importante la influencia del tipo de discurso ( $p$-valor $=0,046)$ ya que se valora como más agradable el discurso espontáneo que el leído.

\footnotetext{
A estas variables básicas hemos añadido la variable cercanía o grado de proximidad entre la persona y la voz evaluada. En este caso, en la encuesta se dan seis posibilidades numéricas (desde 6 'idéntica' a 1 'totalmente diferente'). Al tratarse de valoración de la propia variedad, los valores 1 y 2 , así como el 6 eran escasos, de modo que se procedió a la recodificación en tres valores: 3 (valores 1, 2 y 3 originales), 4 y 5 (valores 5 y 6 originales).
} 
2) Monótona/variada. En este caso, como parece esperable, resulta significativa la influencia del tipo de discurso $(\mathrm{p}$-valor $=0,028)$, ya que el discurso leído tiende a ser valorado como más monótono que el espontáneo. Esto se puede comprobar en el gráfico 5.

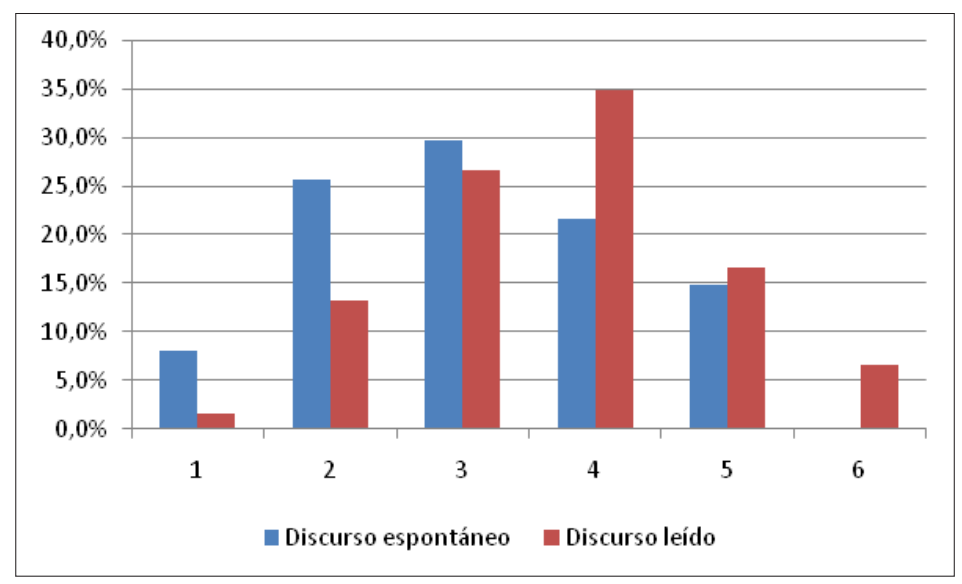

Gráfico 5. Porcentajes de valoraciones sobre monotonía/ variedad según tipo de discurso

Como se puede observar en el gráfico 5, las calificación extrema de monotonía (6) solo se aplica a la lectura, mientras que las calificaciones extremas contrarias $(1=$ variedad $)$ están ocupadas mayoritariamente por el discurso espontáneo. Nótese, además, la acumulación de valores hacia la izquierda (variedad) del discurso espontáneo, frente a la acumulación de valores hacia la derecha (monotonía) del discurso leído.

3) Blanda/Dura. La supuesta dureza o blandura de las voces andaluzas evaluadas tienen globalmente una valoración neutra $(3,59$, como queda expuesto en el gráfico 4), pero está significativamente influida por la voz evaluada, masculina o femenina ( $\mathrm{p}$-valor $=0,001)$. Esto se puede comprobar en el gráfico 6 . 


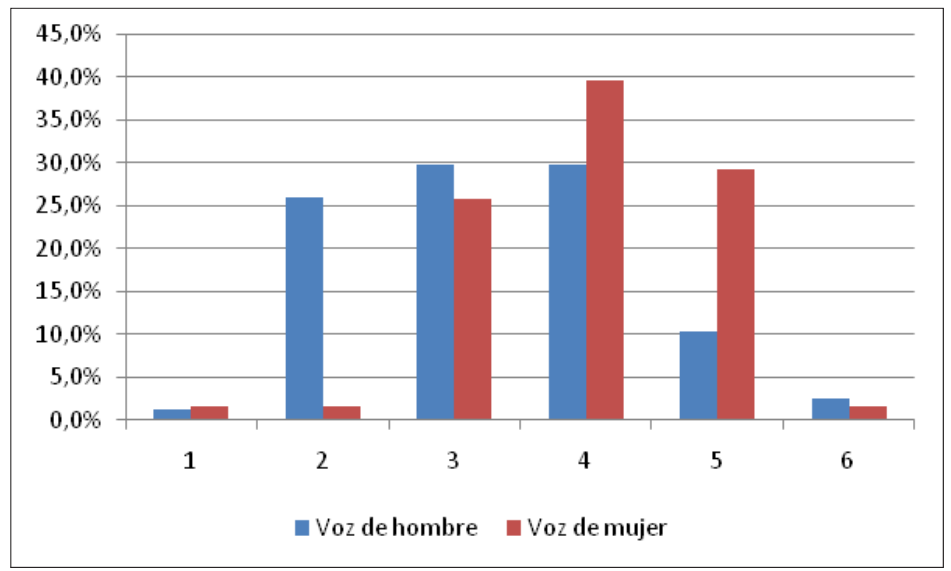

Gráfico 6. Porcentajes de valoraciones sobre blandura/dureza según voz evaluada

En el gráfico 6 se puede observar cómo los valores concedidos a la voz femenina tienden a acumularse a la derecha (más blandura), mientras que la voz masculina muestra valoraciones que tienden hacia los valores de la dureza, situados a la izquierda.

4) Rural/urbana. Como hemos visto en el gráfico 4, la consideración de la variedad andaluza tiende a la ruralidad, pero hay diferencias significativas según la voz evaluada sea masculina o femenina ( $\mathrm{p}$-valor $=0,001)$. Si calculamos los valores solo para la voz masculina, obtenemos un resultado de 3,93, es decir, en el ámbito de la consideración rural; mientras que el valor correspondiente a la voz femenina es de 3,37, que, si tenemos en cuenta que el valor intermedio de la escala es de 3,5, nos sitúa a las voces de mujeres en la urbanidad.

5) Divertida/aburrida. El tipo de discurso es el factor que influye más claramente en la variación de las valoraciones sobre el carácter divertido o aburrido del andaluz ( $\mathrm{p}$-valor $=0,000$ ). El valor global es neutro, pero, como se observa en el gráfico 7, hay diferencias comentables si observamos las valoraciones por separado. 


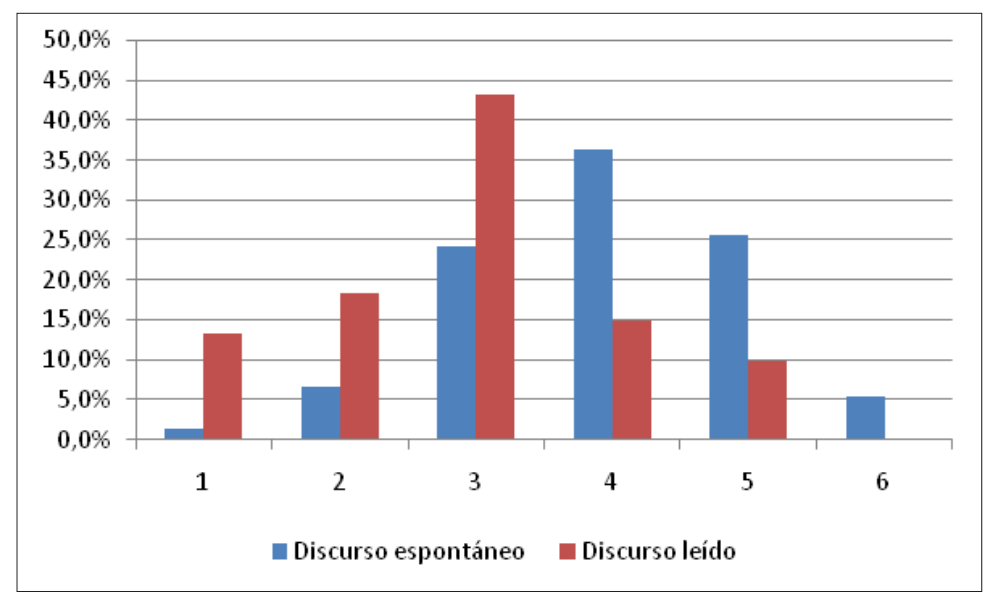

Gráfico 7. Porcentajes de valoraciones sobre divertido/ aburrido según tipo de discurso

El gráfico 7 nos muestra que las valoraciones sobre el discurso espontáneo tienden a desplazarse hacia la derecha (divertido), mientras que las valoraciones otorgadas al discurso leído se desplazan claramente hacia la izquierda (aburrido).

6) Confusa/Clara. La valoración de las voces andaluzas identificadas correctamente sitúa esta variedad en la claridad. No obstante, hay que precisar que influye también significativamente si la voz evaluada es masculina o femenina ( $p$-valor $=0,024)$. La voz menos confusa es la de la mujer, porque hay muchas valoraciones mínimas ( 1 y 2 ) de la voz femenina y esas valoraciones mínimas no aparecen para la voz masculina. No podemos dejar de sospechar que, quizá, pueda influir que la mayoría de los sujetos de encuesta es mujer.

\subsubsection{Valoraciones indirectas del andaluz}

Las valoraciones indirectas se dividen en valoraciones socioeconómicas, personales y regionales.

La valoración socioeconómica sobre la variedad propia de los encuestados granadinos se resume en la tabla 9. 


\begin{tabular}{|l|l|c|c|}
\hline \multicolumn{3}{|c|}{ Valoraciones socioeconómicas } \\
\hline \multirow{4}{*}{ Trabajo } & No contesta & Andaluz $(\mathrm{n}=135)$ & Castellano (n=129) \\
\cline { 2 - 4 } & Poco cualificado & $1 / 0,74 \%$ & $1 / 0,78 \%$ \\
\cline { 2 - 4 } & Bien cualificado & $33 / 24,44 \%$ & $5 / 3,88 \%$ \\
\cline { 2 - 4 } & Altamente cualificado & $92 / 68,15 \%$ & $70 / 54,26 \%$ \\
\hline Ingresos & No contesta & $1 / 6,67 \%$ & $53 / 41,09 \%$ \\
\cline { 2 - 4 } & Bajos & $18 / 13,33 \%$ & $1 / 0,78 \%$ \\
\cline { 2 - 4 } & Medios & $105 / 77,78 \%$ & $1 / 0,78 \%$ \\
\cline { 2 - 4 } & Altos & $11 / 8,15 \%$ & $76 / 58,91 \%$ \\
\hline \multirow{5}{*}{ Estudios } & No contesta & $1 / 0,74 \%$ & $1 / 0,78 \%$ \\
\cline { 2 - 4 } & Sin estudios & $4 / 2,96 \%$ & $0 / 0 \%$ \\
\cline { 2 - 4 } & Primarios & $27 / 20,00 \%$ & $5 / 3,88 \%$ \\
\cline { 2 - 4 } & Secundarios & $70 / 51,85 \%$ & $32 / 24,81 \%$ \\
\cline { 2 - 4 } & Universitarios & $33 / 24,44 \%$ & $91 / 70,54 \%$ \\
\hline
\end{tabular}

Tabla 9. Valoración indirecta sobre la socioeconomía del andaluz y del castellano. Datos absolutos y porcentuales

De la tabla 9 se puede extraer una fácil conclusión: en ningún caso, ni para el puesto de trabajo, ni para el nivel de ingresos, ni en lo concerniente al nivel de estudios, la valoración de las voces andaluzas ocupa los mejores puestos. Esto es especialmente significativo si lo comparamos con la valoración socioeconómica de la variedad castellana, a la que los estudiantes granadinos otorgan una puntuación significativamente más alta en todos los casos.

Asimismo, hay que resaltar que la adscripción socioeconómica es relativamente homogénea, porque hay pocos factores que influyan significativamente en la variación de las valoraciones. Observamos que son significativas las relaciones entre el nivel de estudios y el tipo de discurso ( $\mathrm{p}$-valor $=0,040)$, puesto que el discurso leído implica mayor valoración del nivel de estudios; entre la voz evaluada y el trabajo ( $\mathrm{p}$-valor $=0,015$ ), ya que el trabajo de la voz masculina se considera peor cualificado; $y$, por último, el grado de cercanía para trabajo, ingresos y estudios ( $\mathrm{p}$-valores respectivos de $0,001,0,029$ y 0,001$)$. En estos tres últimos casos hay un factor de simpatía ya que mejora la valoración del trabajo, ingresos y estudios conforme se sienten más cercanos los hablantes. Quizá el dato más llamativo sea el de la consideración de la cualificación del trabajo según la voz. Ofrecemos el gráfico 8 donde se puede apreciar la variación. 


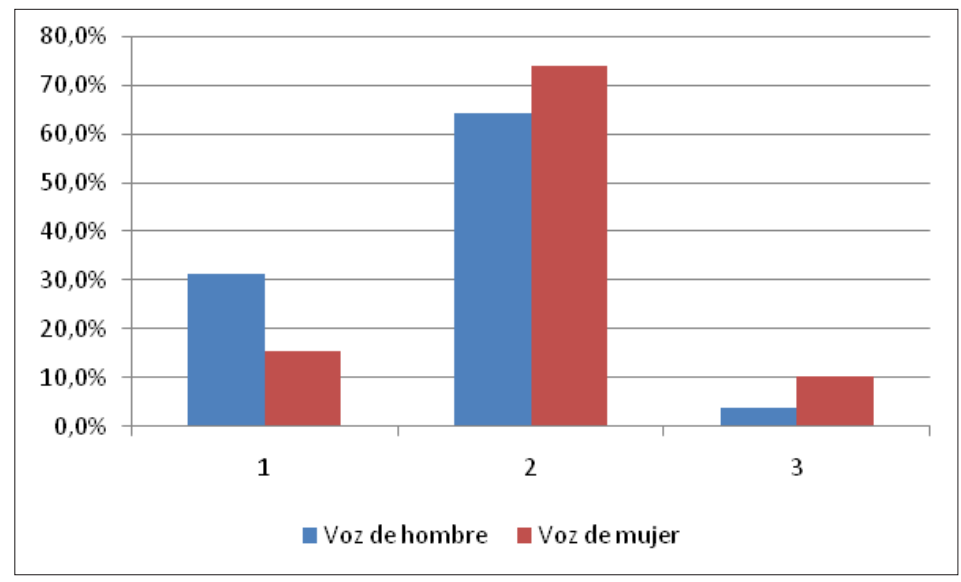

Gráfico 8. Porcentajes de valoración del trabajo según voz evaluada

Se observa en el gráfico 8 que la peor valoración del trabajo (valor 1) está mayoritariamente ocupada por voces de hombre, mientras que la mejor valoración (valor 3) corresponde también en su mayoría a voces de mujer. El valor intermedio no ofrece diferencias importantes entre tipos de voces.

La valoración de las características de la persona que habla arroja unos valores que se pueden observar en el gráfico 9 .

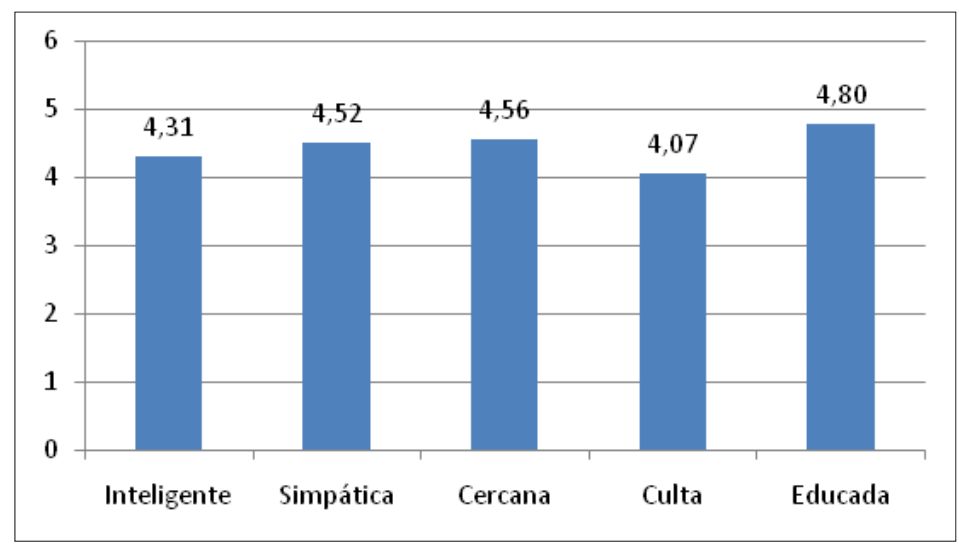

Gráfico 9. Valoración de las características personales de la persona que habla (origen de $y=3,60$ )

Es evidente que la valoración de las características personales es muy positiva: la media más baja supera el valor 4. Quizá llama la atención que, 
aún dentro de los altos valores, sean inteligente y, especialmente, culta los más bajos. Creemos que en algunos estudiantes de filología siguen actuando tópicos sobre el nivel educativo de los andaluces, como, por otra parte, también se refleja en la tabla 9 de valoración socioeconómica de las personas que hablan.

También en el caso de la valoración de la persona hay algunos factores significativos en la explicación de las diferencias de las valoraciones otorgadas. En este caso enumeramos los factores que resultan significativos ( $p$-valor $<0,05$ ) y las valoraciones afectadas:

1) El sexo del encuestado influye únicamente en la valoración sobre la supuesta cultura o incultura de las personas que hablan $(\mathrm{p}$-valor $=0,041)$. Si representamos la distribución de porcentajes obtenemos el gráfico 10.

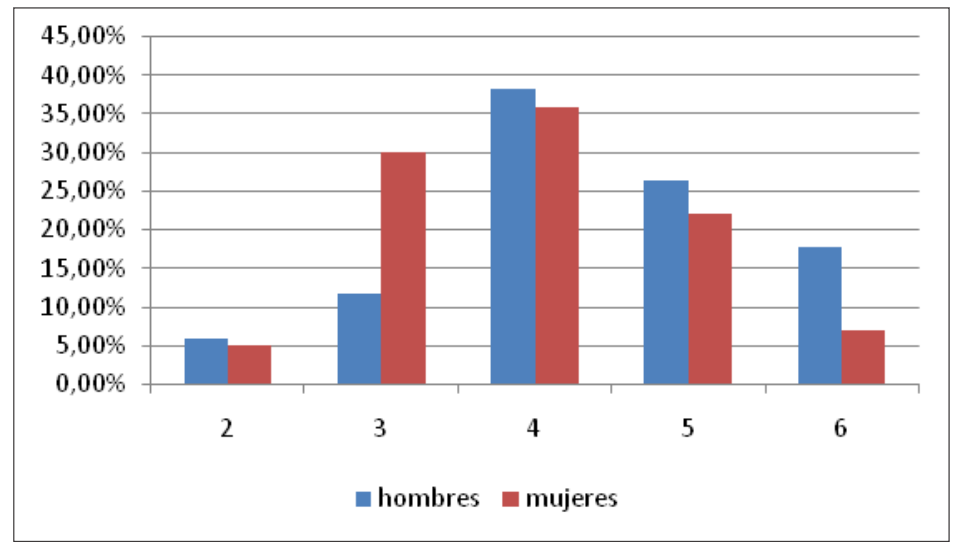

Gráfico 10. Porcentajes de valoraciones de culta/ inculta según el factor sexo del encuestado

Sorprende en buena medida que sean las mujeres las que tiendan a calificar como más incultas a los andaluces que han prestado su voz para la encuesta, como se puede observar por el relativo desplazamiento hacia los valores menores (izquierda del gráfico 10), mientras que en los hombres se observa un desplazamiento hacia los valores mayores. Quizá la explicación de este sorprendente dato tenga que ver con la lealtad de grupo y el prestigio lingüístico: es posible que las mujeres tiendan a evaluar negativamente la voz masculina -que, no lo olvidemos, supone la mitad de los textos evaluados-, mientras que los hombres no hacen distingos en la valoración según el sexo de la persona que habla. 
2) El factor colectivo prevariedad o postvariedad influye significativamente en la variación de la valoración de la inteligencia $(\mathrm{p}$-valor $=0,023)$ y la cultura $(\mathrm{p}$-valor $=0,003)$ de la persona que habla. El colectivo que ya ha estudiado variedades del español valora mejor la inteligencia de la persona que habla que el colectivo prevariedades. La influencia de los colectivos en la distribución de los valores de la cultura podemos observarla en el gráfico 11.

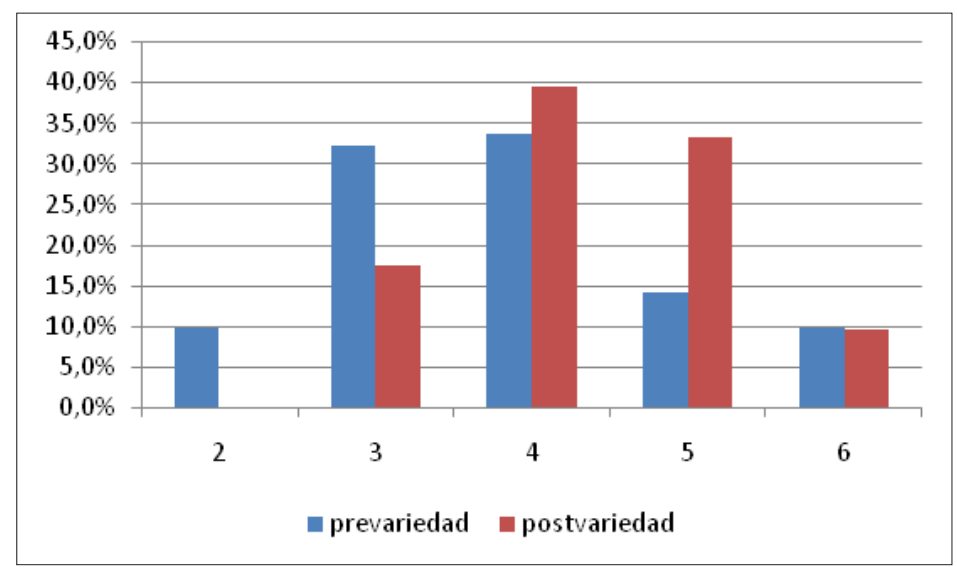

Gráfico 11. Porcentajes superpuestos de valoraciones de culta/ inculta para la persona que habla según el colectivo

Del gráfico 11 se destaca que los alumnos que ya han estudiado cursos sobre variedades del español dan una valoración mucho más positiva que los que no han cursado este tipo de materias. Obsérvese, por ejemplo, que no hay ninguna valoración con valor 2 de los alumnos del colectivo postvariedades.

3) El tipo de discurso oral o leído influye en la distribución de las valoraciones tanto de la simpatía ( $\mathrm{p}$-valor $=0,001)$ como de la cercanía ( $\mathrm{p}$-valor $=0,000)$. Las personas que leen son vistas como menos simpáticas que aquellas que ofrecen un texto más espontáneo. Del mismo modo, como se refleja en el gráfico 12, se considera más cercana la variedad no leída. 


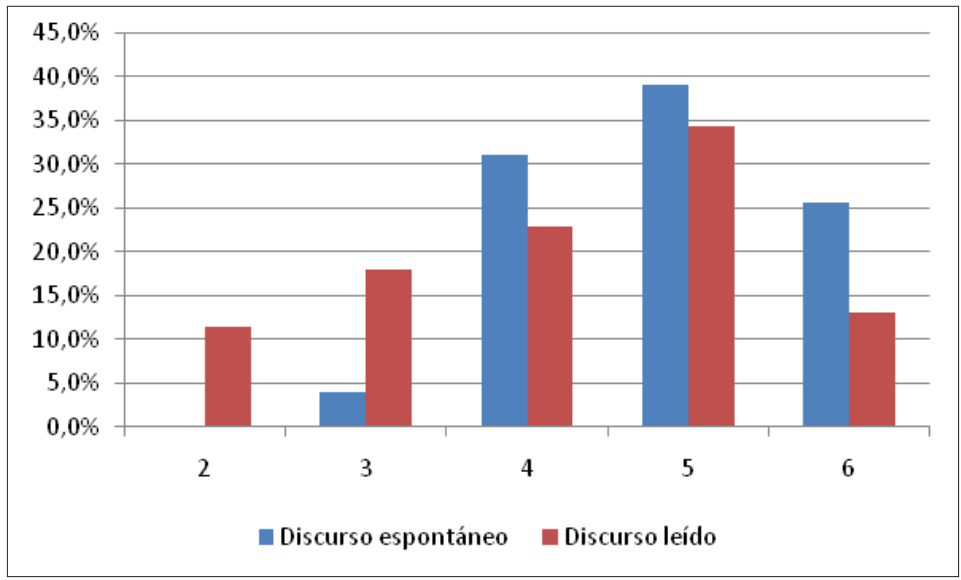

Gráfico 12. Porcentajes de valoraciones de cercana/distante según tipo de discurso

Debe notarse en el gráfico 12 que el discurso más espontáneo no recibe ninguna valoración 2 y muy pocas 3 , por lo que su distribución se desplaza hacia los valores de la derecha, con lo que su valoración es claramente mejor que la del discurso leído.

4) La voz evaluada (masculina o femenina) solo influye significativamente en la valoración de la inteligencia de la persona que habla ( $\mathrm{p}$-valor $=0,043$ ). Es algo más positiva esa valoración en el caso de la voz femenina. Recordemos que la mayoría de los sujetos encuestados es mujer (ver tabla 1).

La valoración de la región a través de las voces de las personas se muestra en el gráfico 13.

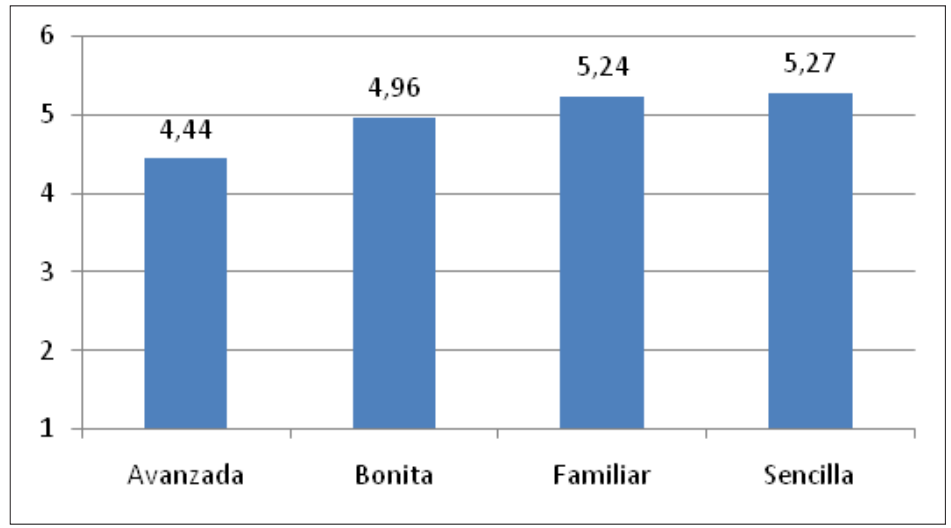

Gráfico 13. Valoración indirecta: valoración de la zona 
Es evidente que la valoración es muy alta: en todos los casos se supera el 4 y en dos de ellos (zona familiar y zona sencilla) se acerca al máximo. Debemos, en este punto, recordar que no parecen afectar a estos alumnos los intentos de potenciar las diferencias localistas entre el oriente y el occidente andaluz. Tampoco podemos dejar de comentar que la valoración relativamente más baja es la que se otorga al grado de avance de Andalucía. Es otro dato que vuelve a estar en consonancia con la valoración socioeconómica que mostramos en la tabla 9.

También nos vemos obligados a reseñar que aparecen diferencias reseñables en la valoración de la zona si se contemplan los errores de adscripción a Andalucía. A pesar de que las valoraciones son altas, son en todos los casos más bajas que en las adscripciones correctas: avanzada $=4,06$; bonita $=4,70 ;$ familiar $=4,91$; sencilla $=5,02$. Parecen operar factores psicosociolingüísticos profundos que matizan las lealtades regionales según sea la voz oída.

Por otra parte, es llamativa la homogeneidad de las valoraciones en este apartado, ya que solo hay un factor significativo en la explicación de la variación. Se trata del tipo de discurso que resulta significativo en la distribución de los valores de avanzado/retrasado ( $\mathrm{p}$-valor $=0,043$ ). Los alumnos granadinos consideran a la región algo más avanzada si valoran el discurso leído.

El último aspecto evaluado en este apartado de evaluaciones indirectas es la cultura del país o zona. La media de las valoraciones se ofrece en el gráfico 14.

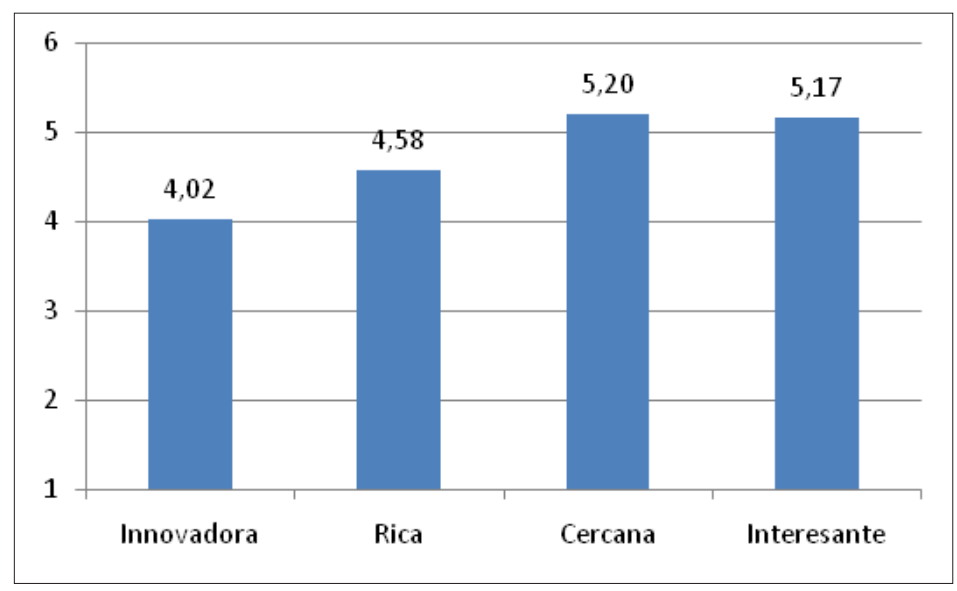

Gráfico 14. Valoración indirecta: valoración de la cultura de la zona 
Como en el caso de la valoración de la zona, el gráfico 14 muestra una alta valoración de la cultura de Andalucía. Parece lógico que lo más valorado sea la cercanía. No deja de ser sintomática la relativa baja consideración de la cultura andaluza en cuanto a su carácter innovador. Seguramente aquí actúan tópicos profundamente arraigados en el inconsciente de los andaluces, al menos de algunos de los que conforman la muestra: consideración de comunidad rural y consiguiente adscripción a la tradición, consideración del flamenco como manifestación antigua, etc.

Otra vez vuelven a surgir algunas diferencias si observamos las medias de valoración de los falsos andaluces. Vuelven a ser en todos los casos más bajas: innovadora $=3,70 ;$ rica $=4,45$, cercana $=5,02 ; \mathrm{y}$, por último, interesante es prácticamente igual porque hemos obtenido un valor de 5,15.

Al igual que en el apartado de valoración de la zona, los datos correspondientes a la cultura son muy homogéneos. Solo hay un factor que haya resultado significativo en la explicación de la variación, pero es muy interesante: la voz evaluada influye en la consideración de la riqueza de la cultura ( $\mathrm{p}$-valor $=0,014)$. La distribución de los porcentajes la ofrecemos en el gráfico 15.

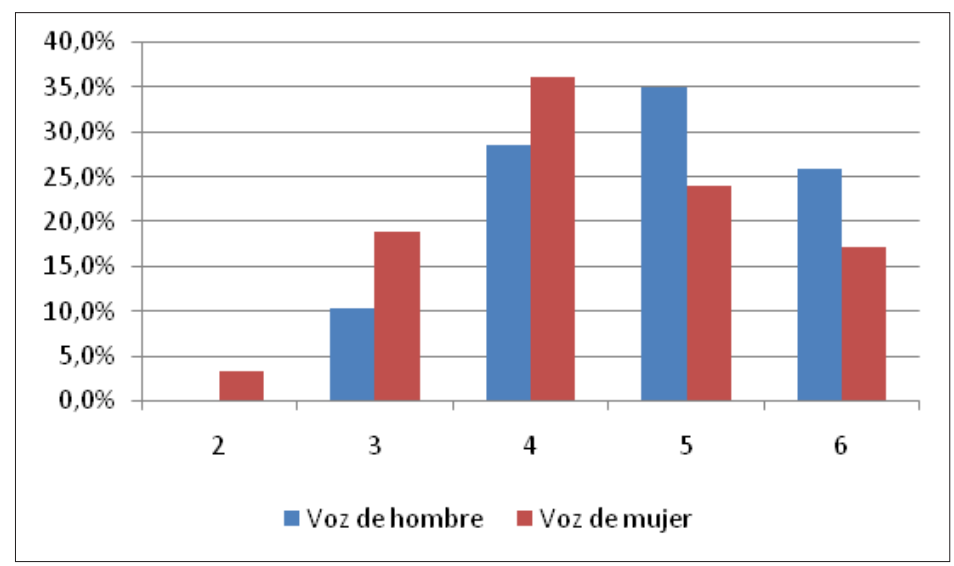

Gráfico 15. Porcentajes superpuestos de valoraciones de rica/pobre según voz evaluada

Se observa en el gráfico 15 que la voz de hombre proporciona mejores valoraciones por el desplazamiento hacia la derecha de las valoraciones, mientras que la voz de mujer obtiene significativas adscripciones a los valores más bajos. Es este uno de los pocos datos donde los sujetos encuestados atribuyen características peores a la voz de mujer que a la voz de hombre. 


\section{CONCLUSIONES}

El estudio muestra los resultados de una encuesta sobre actitudes y creencias realizada a un grupo especial: futuros profesores de español, tanto en su vertiente de lengua materna, como en su aspecto de lengua extranjera; todos ellos granadinos y estudiantes de Filología Hispánica. Debemos recordar que este colectivo es uno de los transmisores del prestigio lingüístico y que su proyección futura será, pues, importante. Tras el análisis de los resultados obtenidos estamos en condiciones de responder a las tres preguntas planteadas al inicio del artículo.

La primera pregunta planteaba si para los sujetos estudiados existe alguna variedad de español que pueda considerarse mejor o más prestigiosa. A esta cuestión tenemos que responder afirmativamente, ya que casi en la mitad de los encuestados pervive la creencia de la existencia de un mejor español, localizado en el centro-norte de la península ibérica. En este apartado no podemos dejar de apuntar que la existencia de jerarquías está ligada a la educación, puesto que el colectivo que ha estudiado materias relacionadas con las variedades del español tiende a no establecer jerarquías, frente a los que aún no han cursado este tipo de materias. Dos corolarios se extraen de estos datos: a) son necesarias las materias de cariz sociolingüístico en los diseños de los grados universitarios y b) algo está fallando en la educación secundaria en Andalucía porque los alumnos recién llegados a la universidad tienen una visión muy jerarquizada de las variedades del español.

Asimismo, no podemos dejar de apuntar la fortísima mediación de la escritura en las consideraciones sobre la preeminencia del castellano. Los tópicos sobre el sistema gráfico actúan para considerar mejores las variedades donde se pronuncian todas las letras y se tienden a minusvalorar otras, como la propia, donde se pondera como negativa la falta de pronunciación de todas las vocales y consonantes. Sin duda es un bien que los hispanohablantes tengamos un único sistema ortográfico, pero no estaría de más hacer hincapié a estos alumnos sobre que una cosa es la escritura y otra la oralidad.

La segunda pregunta inquiría sobre en qué medida los estudiantes granadinos identifican y valoran el resto de variedades cultas del español. Ahora podemos responder que, excepto la variedad rioplatense, seguramente por cuestiones de fonética relevantes perceptivamente -en especial la fonética de algunas palatales- el reconocimiento es mucho menor para las variedades americanas que para las españolas. De estas últimas, también es llamativa la elevada proporción de errores de adscripción de la variedad canaria, bien a variedades americanas, bien a la propia variedad andaluza. 
En el bajo grado de identificación de las variedades americanas destaca, sin duda, la chilena, que es escasísimamente acertada.

La tercera pregunta versa sobre la variedad propia, es decir, ¿qué percepción tienen los futuros docentes granadinos de su propia variedad? Tenemos que señalar, para este apartado, que el porcentaje de identificación de las voces andaluzas ha sido alto y que el grado de identificación con esos discursos ha sido también elevado, aunque los encuestados han preferido no identificarse con la valoración extrema (totalmente idéntica), sino con identificaciones más ponderadas. Esto nos lleva a concluir, por una parte, que los sujetos de encuesta tienen conciencia de que su variedad local (oriental andaluza) tiene algunos rasgos diferenciadores respecto a las voces evaluadas (occidentales andaluzas), pero no operan en ellos los intentos de presentar el andaluz como fragmentado en exceso. Parece evidente que, para estos alumnos, desde el punto de vista de las valoraciones, el andaluz existe.

Las valoraciones directas de las voces andaluzas tienden a ser positivas, aunque, en algún caso, pervivan ciertos tópicos que lastran la consideración de la propia variedad de los encuestados. Es el caso de la creencia de que el andaluz tiene un carácter más rural que urbano, desmentido por la realidad social actual.

Las valoraciones indirectas son aparentemente contradictorias, ya que, por una parte, se otorga una relativamente negativa situación socioeconómica a los hablantes andaluces, mientras que, por otra parte, las valoraciones de la región y de la cultura propias son positivas. Creemos que las valoraciones contradictorias se pueden explicar porque sobre los encuestados actúan dos polos: hay una visión, quizá tópica, muy positiva de la región (bonita, interesante) y sus habitantes (graciosos, agradables, amables), pero sigue pesando la estigmatización de muchos rasgos lingüísticos andaluces, que llevan a asociar al andaluz con el nivel sociocultural bajo o a degradarlo a la categoría de jerga.

Estas consideraciones, en algún caso, hay que matizarlas porque hemos demostrado a lo largo del artículo que hay algunos factores que contribuyen a la variación de las valoraciones subjetivas de los encuestados. Es importante en no pocos casos la pertenencia al colectivo que no ha cursado materias sociolingüísticas o al que ya las ha cursado. Pero también es pertinente si la voz evaluada es de hombre o de mujer: en la mayoría de los casos, las respuestas apuntan a la consideración más prestigiosa de las voces femeninas. Asimismo, los textos leídos, frente a los más espontáneos, proporcionan valoraciones más negativas en lo que toca a las valoraciones directas. El sexo de los encuestados, sin embargo, casi nunca ha arrojado valores significativos para explicar la variación de las opiniones expresadas. 
Queda mucho por investigar porque las encuestas de PRECAVES XXI proporcionan una información riquísima, pero, sin duda, de la comparación de los datos de este trabajo con otros de este proyecto se podrán extraer otras conclusiones más abarcadoras de las actitudes y creencias lingüísticas del mundo hispánico.

\section{REFERENCIAS BIBLIOGRÁFICAS}

Alcaraz Masats, Felipe et al. 1979. El andaluz. Informe sobre la conciencia lingüistica en Andalucía. Dpto. de Lingüística y Crítica Literararia. Colegio Universitario de Jaén.

Alvar López, Manuel. 1999. Entrevista a Manuel Alvar, filólogo y exdirector de la Real Academia Española. El País. 30 de noviembre de 1999. Disponible en https://elpais.com/ diario/1999/11/30/andalucia/943917753_850215.html [Consulta =1/12/2017].

Cano Aguilar, Rafael. 2013. El proceso histórico de constitución de las hablas andaluzas: revisión crítica de las hipótesis emitidas. En Antonio Narbona Jiménez (dir.). Conciencia y valoración del habla andaluza. Sevilla: Univ. Internacional de Andalucía.

Cestero Mancera, Ana M. y Florentino Paredes García. 2018. Creencias y actitudes hacia las variedades cultas del español actual: el proyecto PRECAVES XXI. Boletín de Filología (este volumen).

Crespo Cano, Virgilio y Antonio Manjón-Cabeza Cruz. 1996. Aproximación a las actitudes y creencias lingüísticas de futuros maestros. Docencia e Investigación 21: 41-76.

De Bustos Tovar, José Jesús. 1981. El habla andaluza. Historia de Andalucía. Vol. 5, pp. 19-39. Barcelona: Editorial CUPSA/ Planeta.

1996. El concepto de conciencia lingüística y las hablas andaluzas. Las lenguas de España. Sevilla: Fundación El Monte, pp. 267-280.

De Molina Redondo, José Andrés. 1985. Las lenguas de España después de la Constitución de 1978: el andaluz (sintaxis). Revista de filología románica 3: 69-76.

Frago Gracia, Juan Antonio. 1993. Historia de las hablas andaluzas. Madrid: Arco/Libros.

Fuentes González, Antonio Daniel. 1996. Actitudes sociolingüisticas de la ciudad de Almería. Almería: GRUSTA.

García Marcos, Francisco. 2008. Bases de planificación lingüistica de Andalucía. Univ. de Almería.

y Antonio Daniel Fuentes GonZález. 1996. Mecanismos de prestigio y repercusión sociolingüistica. Univ. de Almería.

y Antonio Manjón-Cabeza Cruz. 1989. Creencias lingüísticas en la E.G.B. Contribución a una política lingüística en Andalucía. Actas del V Congreso Nacional de AESLA. Pamplona: Univ. de Navarra, pp. 243-249.

LAPesa, Rafael. 2008. Historia de la lengua española. Madrid: Gredos, $8^{\mathrm{a}}$ ed.

MAnjón-CABeZa CruZ, Antonio. 2000. Actitudes de los transmisores del prestigio lingüístico en Toledo: primeros datos. Docencia e Investigación 25: 89-123.

Martínez, María y Juan Antonio Moya Corral. 2000. Reacciones actitudinales hacia la variación dialectal en hablantes granadinos. Lingüistica Española Actual XXII/2: 137-156.

Mondésar Cumpián, José. 1985. El español, el español meridional y la Constitución de 1978. Revista de filología románica III: 47-67. 
2006. Bibliografía sistemática y cronológica de las hablas andaluzas. Universidad de Málaga / Universidad de Granada. $2^{\mathrm{a}}$ ed.

Moreno Cabrera, Juan Carlos. 2006. La dignidad e igualdad de las lenguas. Crítica de la discriminación lingüística. Madrid: Alianza.

Narbona Jiménez, Antonio (coord.). 2009. La identidad lingüística de Andalucía. Sevilla: Junta de Andalucía.

Narbona, Antonio; Rafael Cano y Ramón Morillo. 1998. El español hablado en Andalucía. Barcelona: Ariel.

Narbona, Antonio y Ramón Morillo-Velarde. 1987. Las hablas andaluzas. Córdoba: Cajasur.

ROMERA BARRIOS, LOURDES. 1999. La pronunciación de las letras (pesadilla de una profesora de fonología). Homenatge a Jesús Tusón. Barcelona: Empúries.

Trudgill, Peter. 1983. Sociolinguistics: An introduction to language and society. Hardmondsworth: Penguin.

Vaz de Soto, José María. 1981. Defensa del habla andaluza. Sevilla: Edisur.

VILLENA PONSODA, JUAN ANDRÉs. 2006. Andaluz oriental y andaluz occidental: estandarización y planificación en ¿una o dos comunidades de habla? En Ana Cestero, Isabel Molina, y Florentino Paredes (eds.). Estudios sociolingüisticos del español de España y América, pp. 233-254. Madrid: Arco/Libros.

Yraola, Aitor. 2014. Actitudes lingüísticas en España. En Ana Beatriz Chiquito y Miguel Ángel Quesada Pacheco (eds.). Actitudes lingüisticas de los hispanohablantes hacia el idioma español y sus variantes. Bergen Language and Linguistic Studies (BeLLS), 5. Disponible en http://dx.doi.org/10.15845/bells.v5i0.685 